\title{
Genetic diversity of Streptococcus agalactiae strains and density of vaginal carriage
}

\begin{abstract}
Correspondence
Nathalie van der Mee-Marquet n.vandermee@chu-tours.fr
\end{abstract}

Received 13 August 2008

Accepted 28 October 2008

\author{
Nathalie van der Mee-Marquet, ${ }^{1,2}$ Cindy Jouannet, ${ }^{2}$ \\ Anne-Sophie Domelier, ${ }^{1,2}$ Laurence Arnault, ${ }^{2}$ Marie-Frédérique Lartigue ${ }^{1,2}$ \\ and Roland Quentin ${ }^{1,2}$ \\ ${ }^{1}$ Université François-Rabelais, IFR 136, Faculté de Médecine, EA 3854 Bactéries et Risque \\ Materno-Fœtal, Tours, France \\ ${ }^{2}$ Laboratoire de Bactériologie et Hygiène, Hôpital Trousseau, CHU, 37044 Tours cedex, France
}

\section{INTRODUCTION}

Streptococcus agalactiae is the most common pathogen responsible for materno-fetal and neonatal infections. Prevention of severe neonatal meningitis, pneumonia and sepsis associated with $S$. agalactiae requires detection of vaginal carriage in pregnant women, followed by penicillin treatment preceding delivery. Various methods, mostly involving culture, are used for the detection of vaginal carriage (Jones et al., 2003; Musser et al., 1989; Rallu et al., 2006; Schrag et al., 2002; Takahashi et al., 1998).

Serotype III multilocus sequence type 17 (ST-17) strains account for most neonatal infections (Quentin et al., 1995; Lin et al., 2006; Bohnsack et al., 2008). In addition, genetic markers have been associated with virulent phylogenetic subgroups of strains. These are the insertion sequence IS1548 in the hylB gene (Granlund et al., 2001), a group II intron GBSil that is located downstream from the C5apeptidase gene $\operatorname{spB} B$ (Rolland et al., 1999) and the presence of particular prophage DNA fragments in the S. agalactiae genome (van der Mee-Marquet et al., 2006).

Here, we report the results of screening for vaginal carriage of $S$. agalactiae in 500 pregnant women in France using a procedure recommended by the Agence Nationale

Abbreviations: $H$, heavy [carriage]; I, intermediate [carriage]; L, light [carriage]; ST-17, sequence type 17.

A supplementary table is available with the online version of this paper.
d'Accréditation et d'Évaluation en Santé (2001). The density of carriage was evaluated by using a semiquantitative method. Serotyping, PFGE analysis and PCR screening for ST-17 clones and five genetic markers of virulent $S$. agalactiae subgroups were used to assess the genetic diversity of the strains. Our findings shed some light on the link between the density of $S$. agalactiae vaginal carriage in pregnant women and the genetic diversity and characteristics of the strains.

\section{METHODS}

Bacterial strains. Five hundred pregnant women who attended the Gynaecology Department of the teaching hospital of Tours, France, over a 3-month period were sampled 35-38 weeks before delivery, in accordance with French recommendations (Agence Nationale d'Accréditation et d'Évaluation en Santé, 2001). A vaginal swab was collected from each patient and transferred immediately to the microbiological laboratory. Swabs were subsequently plated on a Strepto B agar plate and used to inoculate a Strepto B agar tube (AES Laboratoire). Plates and tubes were incubated at $37{ }^{\circ} \mathrm{C}$ for $48 \mathrm{~h}$ under anaerobic conditions. Suspected colonies were tested for catalase and tested with the Lancefield system (Oxoid); API 20 Strep galleries were used to confirm the identification. Cultures on plates were semiquantified (on a scale from $1+$ to $4+$ ) according to the number of quarters of the plate with growth. The tube culture was interpreted as positive or negative as recommended by the manufacturer. Vaginal carriage was defined as heavy (designated $\mathrm{H}$ ) when the tube culture was positive and the plate scored $3+$ or $4+$, as intermediate (I) when the tube culture was positive and the plate scored $1+$ or $2+$ and as light $(\mathrm{L})$ when only one of either the tube or plate cultures was positive. 
PCR screening for ST-17. The ST-17 clone was detected by using a real-time PCR with primers for screening of the ST-17 clone (Supplementary Table S1, available in JMM Online), which amplify the $g b s 2018$ gene variant encoding a surface protein, that is specific for the ST-17 clone, as described by Lamy et al. (2006). The additional primer set dltR/dltRAS (Lamy et al., 2006), which amplifies the dltR regulation gene present in all $S$. agalactiae strains, was used as an amplification control. The PCR assay was performed on a Chromo 4 System Instrument (Bio-Rad) in a final volume of $25 \mu \mathrm{l}$, containing $5 \mu \mathrm{l}$ extracted DNA, $0.5 \mu \mathrm{M}$ each primer and 1 unit iQ SYBR green Supermix (Qiagen), including $3 \mathrm{mM} \mathrm{MgCl}$. Amplification involved 40 cycles of $10 \mathrm{~s}$ at $95{ }^{\circ} \mathrm{C}, 5 \mathrm{~s}$ at $55^{\circ} \mathrm{C}$ and $10 \mathrm{~s}$ at $72{ }^{\circ} \mathrm{C}$. The reaction product was then cooled to $35^{\circ} \mathrm{C}$ and subjected to a post-PCR melting cycle by elevating the temperature by $0.2{ }^{\circ} \mathrm{C}$ every $10 \mathrm{~s}$, up to $95{ }^{\circ} \mathrm{C}$.

Detection of genetic markers of virulent S. agalactiae strains. The isolated strains were serotyped using PCR (Kong et al., 2002). As previously shown, strains able to invade the central nervous system of neonates frequently carry certain genetic markers at significant levels. Two of these markers are mobile genetic elements [the GBSil group II intron downstream from the C5a-peptidase $s c p B$ gene (Rolland et al., 1999) and IS 1548 in the $h y l B$ gene, which encodes a hyaluronate lyase (Granlund et al., 2001)] and three are prophagic DNA fragments (van der Mee-Marquet et al., 2006). PCR was used to test for the presence of these genetic markers as previously described (Bidet et al., 2003; Rolland et al., 1999; van der Mee-Marquet et al., 2006) (see Supplementary Table S1 for primers).

PFGE. The genetic diversity of the isolated strains was studied by SmaI DNA macrorestriction. DNA was extracted from the isolates, digested with SmaI and then subjected to PFGE, as described previously (Rolland et al., 1999). The gels were stained with ethidium bromide and photographed with a Polaroid instant camera. The PFGE profiles were analysed with the Taxotron package (Taxolab; Institut Pasteur, Paris, France). The images were transferred to a microcomputer, and the distances migrated by each band in each lane were determined in pixel units by RestrictoScan. The size of each fragment was calculated from the distance migrated using cubic Schaffer and Sederoff method algorithms with RestrictoTyper. This software also generated a schematic representation of electrophoretic patterns and produced a distance matrix. The relationships between pulsotypes were determined by the unweighted pair group method using arithmetic means and the Adanson pulsogrouping program (dissimilarity). A dendrogram was drawn with Dendrograf.

\section{RESULTS}

\section{Carriage rate}

With agar plates, $27(5 \%)$ positive cultures were obtained and $34(7 \%)$ were obtained with tubes; a total of $39(8 \%)$ of the 500 women enrolled in the study were positive for $S$. agalactiae. Vaginal carriage was light (L) in 16 cases (41\%), intermediate (I) in 16 cases $(41 \%)$ and heavy $(\mathrm{H})$ in seven cases (18\%) (Fig. 1).

\section{Characteristics of the $39 \mathrm{~S}$. agalactiae strains (Fig. 1)}

Sixteen of the 39 strains ( $41 \%$ ) belonged to serotype III, 10 to serotype Ia $(26 \%)$, three to serotype Ib $(8 \%)$, three to serotype II (8\%) and seven to serotype V (18\%) (Fig. 1).
Nine strains were positive in the ST-17 PCR (23\%). Twenty strains $(51 \%)$ were positive for the intron GBSil. Four strains $(10 \%)$ were determined to have IS1548 inserted into the $h y l B$ gene. The prophagic DNA elements F5, F7 and F10 were found in one (2\%), 15 (38\%) and 19 (49\%) strains, respectively. Genetic variants were determined according to the absence or presence of the GBSi1 group II intron downstream from the C5a-peptidase $\operatorname{scp} B$ gene, IS 1548 in the $h y l B$ gene and the three prophagic DNA fragments (F5, F7 and F10). Thirteen variants (designated V1-V13) were found (Fig. 1), with 26 strains (67\%) clustering in five major variants (V1-V3, V10 and V11).

\section{Genetic diversity of the 39 S. agalactiae strains (Fig. 1)}

DNA macrorestriction of the 39 strains identified 39 different PFGE profiles. The strains clustered mostly (36 strains) in two major divisions named A (17 strains) and B (19 strains). Most division A strains were serotype III (9/17; $53 \%)$ and division B contained numerous serotype I strains $(9 / 19 ; 47 \%)$. Eight of the nine ST-17 strains were in PFGE division A and one was in PFGE division B.

The prevalence of strains carrying the genetic markers that were tested for was significantly higher in division A than in division $\mathrm{B} ; 13$ of 17 (76\%) strains in division $\mathrm{A}$ had two or more markers, whereas these were possessed by only four of $19(21 \%)$ strains in division B $(P<0.001)$. Variants V1-V8 were significantly associated with division $A$ and variants V9-V13 with division B $(P<0.001)$.

\section{Density of S. agalactiae carriage and characteristics of strains}

The density of vaginal carriage was $\mathrm{H}$ in seven cases, I in 16 cases and L in 16 cases (Table 1). There was no significant association between the density of carriage and the strain serotype. Nevertheless, serotype III strains were mostly involved in L carriage (nine cases for 16 serotype III strains) and serotype $\mathrm{V}$ strains in I carriage (five cases for seven serotype $\mathrm{V}$ strains).

The nine ST-17-positive strains, all of serotype III, were mostly involved in cases of L carriage (6/9), but the association was not significant $(P=0.082)$. The density of carriage was similar for strains of division $\mathrm{A}$ and $\mathrm{B}$; numbers in each group were eight $\mathrm{L}$, seven I and two $\mathrm{H}$ for the 17 strains of division $\mathrm{A}$, and seven $\mathrm{L}$, eight $\mathrm{I}$ and four $\mathrm{H}$ for the 19 strains of division B (Fig. 1).

The density of carriage was not significantly associated with the presence or absence of the five genetic markers studied or the distribution the five major genetic variants between the strains (Table 1). Nevertheless, 10 of the 16 GBSi1positive strains were involved in L carriage, nine of the 16 F7-positive strains were isolated from I carriage and 10 of the 13 strains belonging to genetic variants 1 and 2 were from cases of L carriage. 


\begin{tabular}{|c|c|c|c|c|c|c|c|c|c|c|}
\hline \multicolumn{10}{|c|}{ Strain characteristics } & \multirow{2}{*}{$\begin{array}{l}\text { Culture } \\
\text { density }\end{array}$} \\
\hline \multicolumn{2}{|c|}{ Smal macrorestriction patterns } & \multirow[t]{2}{*}{ Serotype } & \multicolumn{7}{|c|}{ Genetic markers } & \\
\hline 0.80 .5 & $\begin{array}{ll}05 & 1 \\
-1, & 1\end{array}$ & & $\begin{array}{c}\text { PCR } \\
\text { ST-17 }\end{array}$ & GBSi1 & IS1548 & F5 & $\mathrm{F} 7$ & F10 & Var & \\
\hline & $\|\quad||||\| \mid$ & III & + & + & & & & + & 1 & $\mathrm{~L}$ \\
\hline & $\| \quad \mid 11111$ & III & + & + & & & & + & 1 & L \\
\hline & $\| \quad|| \mid 1$ & $\mathrm{lb}$ & & + & & & & & 2 & $\mathrm{H}$ \\
\hline & III $\quad$ I $|I I|||$ & III & + & + & & & + & + & 3 & I \\
\hline & III I IIII I & la & & & + & & + & + & 4 & I \\
\hline & $11 \quad|1|$ & $\mathrm{lb}$ & & + & & & + & + & 5 & L \\
\hline & & III & + & + & & & + & + & 3 & $\mathrm{H}$ \\
\hline & $\||| \mid I\|\|\|$ & $\|$ & & + & & & + & + & 3 & L \\
\hline & $\|||\||\||$ & $\|$ & & + & + & & + & & 6 & 1 \\
\hline & |||||||||||| & III & & & & & & + & 7 & L \\
\hline & $\begin{array}{llll}\| & \mid & \mid & \|1\|\|\|\end{array}$ & V & & + & & + & + & + & 8 & I \\
\hline & I I IIII & v & & + & & & & + & 1 & I \\
\hline$A$ & $\||||||||||| \mid$ & III & + & + & + & & & & 2 & $\mathrm{~L}$ \\
\hline & $|\||||||||$ & la & & & & & + & & 9 & I \\
\hline & \|\|$\||||| \mid$ & III & + & + & & & & & 2 & I \\
\hline & $\|\quad\| \quad||||||$ & III & + & + & & & & + & 1 & L \\
\hline & $\| I I \quad$ I $\quad$ IIIII & III & + & + & & & & & 2 & L \\
\hline & $\|\quad\|\|\|$ & $\mathrm{V}$ & & & & & & & nt & L \\
\hline & II I & III & & & & & + & & 10 & 1 \\
\hline & $\||| \quad|\quad||\||$ & la & & & & & & + & 11 & 1 \\
\hline & $\| I|\quad| 1||$ & la & & & & & + & & 10 & $\mathrm{H}$ \\
\hline & |IIIII & la & & & & & & + & 11 & 1 \\
\hline & $\|1|\quad| 1\| 1 \mid$ & la & & & + & & + & & 10 & L \\
\hline & 11111111 & la & & + & & & & + & 12 & $\mathrm{H}$ \\
\hline & |||||||||||||| & la & & & & & & + & 11 & L \\
\hline & $111 \quad 1111$ & III & & + & & & & & 2 & L \\
\hline & $111 \mid 1111$ & la & & & & & & + & 11 & I \\
\hline & 11111111 & la & & & & & & & $\mathrm{nt}$ & L \\
\hline $\mathrm{B}$ & $\begin{array}{llll}111 & 1 & 1 & 11\end{array}$ & $\mathrm{lb}$ & & & & & + & + & 4 & L \\
\hline & $\||\|\| \| \quad 11| 1$ & III & & & & & & & $\mathrm{nt}$ & $\mathrm{H}$ \\
\hline & |l|| | | $|1|||$ & III & & & & & + & & 10 & I \\
\hline & |II | & III & & & & & & + & 11 & $\mathrm{H}$ \\
\hline & 1111 & V & & & & & & & $\mathrm{nt}$ & 1 \\
\hline & | ||II | & V & & & & & + & & 10 & 1 \\
\hline & \|\|$\| \quad||||$ & III & & + & & & & + & 1 & L \\
\hline & | ||| | | || | & $\mathrm{V}$ & & & & + & + & & 13 & 1 \\
\hline & |||| | ||| ||| || | | & $\|$ & & + & & & & & 2 & 1 \\
\hline & III | || | II & III & + & + & & & & & 2 & L \\
\hline & II $\quad 11$ & $\mathrm{~V}$ & & + & & & & & 2 & $\mathrm{H}$ \\
\hline
\end{tabular}

Fig. 1. Characteristics of the $39 \mathrm{~S}$. agalactiae strains isolated from pregnant women. The culture density, serotype, results from PCR screening for ST-17 clones, the presence of genetic markers of virulent S. agalactiae subgroups and genetic diversity are shown. Var, Genetic variant determined by association of genetic markers; nt, not typable. Density of S. agalactiae vaginal colonization was scored as light $(\mathrm{L})$, intermediate $(\mathrm{I})$ or heavy $(\mathrm{H})$ as described in Methods.

\section{DISCUSSION}

We tested for a link between the density of $S$. agalactiae vaginal carriage in pregnant women, the genetic diversity of strains and the presence of genetic features previously described as markers for strains responsible for neonatal meningitis.

We determined a prevalence of $S$. agalactiae vaginal carriage of $8 \%$, although this was slightly lower than values reported by others, these data are nevertheless in accordance with the findings of recent European studies (Agence Nationale d'Accréditation et d'Évaluation en Santé, 2001). These vaginal strains mostly belonged to serotypes III and Ia, and exhibited substantial genetic diversity; in fact, every strain had a different PFGE profile
(39 profiles for the 39 strains) and the pattern of the presence and absence of mobile genetic elements and prophagic DNA fragments in the genome were similarly diverse (13 variants for 39 strains on the basis of five genetic elements). In accordance with their known clonality (Lamy et al., 2006), the nine ST-17-positive strains by PCR were all of serotype III and clustered into one of the two major PFGE divisions (division A). Nevertheless, these nine strains all gave different PFGE profiles (with a percentage of similarity of $35 \%$ ) and could be classified into variants on the basis of the genetic markers $(n=3)$.

These data indicate that the vagina can be colonized by a large variety of $S$. agalactiae strains. Thus, the vagina 
Table 1. Density of $S$. agalactiae vaginal carriage and genetic characteristics of the strains

\begin{tabular}{|c|c|c|c|c|c|c|c|c|c|c|c|}
\hline \multirow[t]{3}{*}{ Colonization density ${ }^{\star}$} & \multirow{3}{*}{$\begin{array}{l}\text { Total no. } \\
\text { of strains }\end{array}$} & \multicolumn{10}{|c|}{ No. of strains in each group } \\
\hline & & \multicolumn{2}{|c|}{$\begin{array}{c}\text { No. of } \\
\text { markers } \dagger\end{array}$} & \multicolumn{2}{|c|}{ PFGE division } & \multicolumn{5}{|c|}{ Genetic variant $\ddagger$} & \multirow[t]{2}{*}{ PCR ST-17 } \\
\hline & & $<2$ & $\geqslant 2$ & A & B & 1 & 2 & 3 & 10 & 11 & \\
\hline All strains & 39 & 22 & 17 & 17 & 19 & 5 & 8 & 3 & 5 & 4 & 9 \\
\hline $\mathrm{H}$ & 7 & 5 & 2 & 2 & 4 & & 2 & 1 & 1 & & 1 \\
\hline I & 16 & 9 & 7 & 7 & 8 & & 1 & 1 & 3 & 3 & 2 \\
\hline $\mathrm{L}$ & 16 & 8 & 8 & 8 & 7 & 5 & 5 & 1 & 1 & 1 & 6 \\
\hline Serotype I & 13 & 8 & 5 & 4 & 9 & & 1 & & 2 & 4 & \\
\hline $\mathrm{H}$ & 3 & 2 & 1 & 1 & 2 & & 1 & & 1 & & \\
\hline I & 5 & 3 & 2 & 2 & 3 & & & & & 3 & \\
\hline $\mathrm{L}$ & 5 & 3 & 2 & 1 & 4 & & & & 1 & 1 & \\
\hline Serotype III & 16 & 9 & 7 & 9 & 6 & 4 & 5 & 2 & 2 & & 9 \\
\hline $\mathrm{H}$ & 3 & 2 & 1 & 1 & 2 & & & 1 & & & 1 \\
\hline I & 4 & 3 & 1 & 2 & 2 & & 1 & 1 & 2 & & 2 \\
\hline $\mathrm{L}$ & 9 & 4 & 5 & 6 & 2 & 4 & 4 & & & & 6 \\
\hline Serotype V & 7 & 4 & 3 & 2 & 4 & & 1 & & 1 & & \\
\hline $\mathrm{H}$ & 1 & 1 & & & & & 1 & & & & \\
\hline I & 5 & 2 & 3 & 2 & 3 & 1 & & & 1 & & \\
\hline $\mathrm{L}$ & 1 & 1 & & & 1 & & & & & & \\
\hline
\end{tabular}

${ }^{*}$ Density of the $S$. agalactiae vaginal colonization was scored as L, I or $\mathrm{H}$, as described in Methods.

$\dagger$ Number of PCR-positive results for screening GBSi1 group II intron downstream from the C5a-peptidase $s c p B$ gene, IS 1548 in the $h y l B$ gene and the three prophage DNA fragments F5, F7 and F10.

$\ddagger$ Genetic variant determined by association of genetic markers.

appears to be a moderately effective anatomical barrier. The substantial genetic diversity of these strains suggests that the ability of $S$. agalactiae to colonize the vagina is predominantly a consequence of the local vaginal environment, which may or may not provide conditions for survival and growth, rather than of the nature or genetic features of the bacteria.

Several studies using selective media and semi-quantitative culture have demonstrated that both the risk of vertical transmission at the time of delivery and the risk of neonatal infections correlate with the density of vaginal carriage. Neonates born to heavily colonized women are significantly more likely to be colonized and/or infected than those born to lightly colonized women (Anthony \& Okada, 1977). We evaluated the level of carriage using a method based on the density of growth observed in culture. This method was only semi-quantitative, but was nevertheless adequate to define $\mathrm{H}$, I and L levels of carriage. We found that the prevalence of the genetic markers associated with strains responsible for neonatal meningitis were equally represented in the strains of these three different classes of density of carriage. Therefore, dense vaginal inocula, associated with a high risk of neonatal colonization or infection, appeared not to be related to particular strains.

Current guidelines recommend prenatal culture-based screening for $S$. agalactiae colonization for all pregnant women and intrapartum chemoprophylaxis by intravenous administration of antibiotics for all women who are colonized (Agence Nationale d'Accréditation et d'Évaluation en Santé, 2001; Schrag et al., 2002). This approach is more effective than the risk-based approach for preventing perinatal $S$. agalactiae disease but may have adverse effects. Excessive exposure to antibiotics may lead to the emergence of more resistant and/or more virulent pathogens, severe allergic reactions and, in the long term, ecological disturbance of the natural flora and even abnormal immunological development in the children. It would be beneficial to minimize intrapartum and neonatal antibiotic prophylaxis when the colonized mother delivers at term with no risk factors and/or when the colonized neonate has no symptoms. Two research avenues could be explored with this aim in mind: (i) the detection of further markers of strains in the vaginal flora associated with a high risk of invasive disease and (ii) the development of exploitable microbiological methods to quantify precisely the density of vaginal colonization at the time of the delivery.

Work to identify markers of strains associated with a high risk of invasive disease in the vaginal flora should be continued. Although several genetic markers associated with strains responsible for neonatal meningitis have been described already, there is no single marker yet described as being significantly associated with other major S. agalactiae infectious diseases (including chorioamniotitis, pneumonia 
and bacteraemia). In addition, our data indicate that the known genetic markers are prevalent in the vaginal $S$. agalactiae population, highlighting the need to improve our knowledge of this pathogen.

The development of microbiological methods to quantify precisely the density of vaginal colonization at the time of the delivery would be valuable because the attack rate for early onset disease is significantly higher in neonates born from heavily colonized women than from lightly colonized women (Anthony \& Okada, 1977). In our population of pregnant women that were without risk factors, light vaginal colonization was frequent $(44 \%)$. Thus, the development of reliable and cheap tools able to quantify precisely the density of $S$. agalactiae carriage in pregnant women at low risk is a promising approach to limiting intrapartum chemoprophylaxis and its adverse effects. Nevertheless, epidemiological studies will have to be conducted to determine the level of the $S$. agalactiae carriage to be used as a cut-off and thereby optimize the risk/benefit ratio for prophylaxis.

\section{REFERENCES}

Agence Nationale d'Accréditation et d'Évaluation en Santé (2001). Antenatal prevention of the risk of early neonatal bacterial infection. [Online] http://www.has-sante.fr/portail/upload/docs/application/ pdf/Antenatal_prevention.pdf.

Anthony, B. F. \& Okada, D. M. (1977). The emergence of group B streptococci in infections of the newborn infant. Annu Rev Med 28, 355-369.

Bidet, P., Brahimi, N., Chalas, C., Aujard, Y. \& Bingen, E. (2003). Molecular characterization of serotype III group B-Streptococcus isolates causing neonatal meningitis. J Infect Dis 188, 1132-1137.

Bohnsack, J. F., Whiting, A., Gottschalk, M., Dunn, D. M., Weiss, R., Azimi, P. H., Philips, J. B., III, Weisman, L. E., Rhoads, G. G. \& Lin, F.-Y. C. (2008). Population structure of invasive and colonizing strains of Streptococcus agalactiae from neonates of six U.S. academic centers from 1995 to 1999. J Clin Microbiol 46, 1285-1291.

Granlund, M., Michel, F. \& Norgren, M. (2001). Mutually exclusive distribution of IS1548 and GBSil, an active group II intron identified in human isolates of group B streptococci. J Bacteriol 183, 2560-2569.
Jones, N., Bohnsack, J. F., Takahashi, S., Oliver, K. A., Chan, M. S., Kunst, F., Glaser, P., Rusniok, C., Crook, D. W. \& other authors (2003). Multilocus sequence typing system for group B Streptococcus. J Clin Microbiol 41, 2530-2536.

Kong, F., Gowan, S., Martin, D., James, G. \& Gilbert, G. L. (2002). Serotype identification of group $B$ streptococci by PCR and sequencing. J Clin Microbiol 40, 216-226.

Lamy, M. C., Dramsi, S., Billoet, A., Reglier-Poupet, H., Tazi, A., Raymond, J., Guerin, F., Couve, E., Kunst, F. \& other authors (2006). Rapid detection of the "highly virulent" group B Streptococcus ST-17 clone. Microbes Infect 8, 1714-1722.

Lin, F.-Y. C., Whiting, A., Adderson, E., Takahashi, S., Dunn, D. M., Weiss, R., Azimi, P. H., Philips, J. B., III, Weisman, L. E. \& other authors (2006). Phylogenetic lineages of invasive and colonizing strains of serotype III group B streptococci from neonates: a multicenter prospective study. J Clin Microbiol 44, 1257-1261.

Musser, J. M., Mattingly, S. J., Quentin, R., Goudeau, A. \& Selander, R. K. (1989). Identification of a high-virulence clone of type III Streptococcus agalactiae (group B Streptococcus) causing invasive neonatal disease. Proc Natl Acad Sci U S A 86, 4731-4735.

Quentin, R., Huet, H., Wang, F. S., Geslin, P., Goudeau, A. \& Selander, R. K. (1995). Characterization of Streptococcus agalactiae strains by multilocus enzyme genotype and serotype: identification of multiple virulent clone families that cause invasive neonatal disease. J Clin Microbiol 33, 2576-2581.

Rallu, F., Barriga, P., Scrivo, C., Martel-Laferrière, V. \& Laferrière, C. (2006). Sensitivities of antigen detection and PCR assays greatly increased compared to that of the standard culture method for screening for group B Streptococcus carriage in pregnant women. J Clin Microbiol 44, 725-728.

Rolland, K., Marois, C., Siquier, V., Cattier, B. \& Quentin, R. (1999). Genetic features of Streptococcus agalactiae strains causing severe neonatal infections, as revealed by pulsed-field gel electrophoresis and hylB gene analysis. J Clin Microbiol 37, 1892-1898.

Schrag, S., Gorwitz, R., Fultz-Butts, K. \& Schuchat, A. (2002). Prevention of perinatal group B streptococcal disease. Revised guidelines from CDC. MMWR Recomm Rep 51, 1-22.

Takahashi, S., Adderson, E. E., Nagano, Y., Nagano, N., Briesacher, M. R. \& Bohnsack, J. F. (1998). Identification of a highly encapsulated, genetically related group of invasive type III group B streptococci. $J$ Infect Dis 177, 1116-1119.

van der Mee-Marquet, N., Domelier, A. S., Mereghetti, L., Lanotte, P., Rosenau, A., van Leeuwen, W. \& Quentin, R. (2006). Prophagic DNA fragments in Streptococcus agalactiae strains and association with neonatal meningitis. J Clin Microbiol 44, 1049-1058. 